\title{
A Variable-Energy Soft X-Ray Microprobe to Investigate Mechanisms of the Radiation-Induced Bystander Effect.
}

\author{
Melvyn Folkard, Borivoj Vojnovic, Giuseppe Schettino, Kirk Atkinson, Kevin M Prise, Barry D Michael
}

Gray Cancer Institute, PO BO Box100, Mount Vernon Hospital, Northwood, HA6 2JR, UK

\section{Introduction}

There remains a need to improve our understanding of the hazards that arise through occupational and environmental exposures to ionizing radiations. An important aspect of this is the role of non-targeted effects (such as the bystander effect) in the biological response to low dose exposures. Micro-irradiation techniques have become an important method for radiobiolical studies of low-dose effects and non-targeted effects $[1,2,3,4]$. The ability to deliver precise low doses to selected individual cells and to sub-cellular targets makes the microbeam technique very desirable for such studies. The strength of the technique lies in its ability to deliver precise doses of radiation to selected individual cells (or sub-cellular targets). Worldwide, microbeams have been built that make use of focussed or collimated particles, low-energy X-rays and electron sources [5]. For a number of years, the Gray Cancer Institute (GCI) has been closely associated with the development and use of both collimated particle and focussed X-ray sources [6].

Our prototype X-ray microprobe was developed alongside our existing charged-particle microbeam to address problems specific to low LET radiations, or where very precise targeting accuracy and dose delivery are required [7]. This facility was optimised for focusing $278 \mathrm{eV} \mathrm{C}_{\mathrm{K}} \mathrm{X}$-rays; however there are a number of reasons for extending the range of available energies. Therefore, this study has sought to develop a variable-energy soft X-ray microprobe capable of delivering focused $\mathrm{C}_{\mathrm{K}}(0.28 \mathrm{keV}), \mathrm{Al}_{\mathrm{K}}(1.48 \mathrm{keV})$ and notably, $\mathrm{Ti}_{\mathrm{K}}(4.5 \mathrm{keV}) \mathrm{X}$-rays. The original proposal had been to simply replace the current microfocus source, while retaining some of the existing microscopy system. However, funding from additional sources has enabled us to develop the new source to be a complete 'standalone' micro-irradiation facility, including an all-new microscopy system for cell-finding, a new cell-positioning system and new software for experimental control. This added complexity has inevitably increased the development time; however, the result is that we now have an operational facility with extra capabilities not originally envisaged. The facility is shown in figure 1. Another important development that emerged during the latter stages of this project was that our group became closely involved in a consortium that was awarded a grant to develop and exploit new 'smart' methods for focussing low-energy X-rays. The proposed new methods use achromatic reflective optics capable of much higher efficiencies than X-ray optics based on zone-pates (ZPs, the method we currently use). Our involvement is this project is to build a further X-ray microprobe optimised for the new X-ray focussing optics. Given that there was substantial overlap in the aims of this project and our existing DOE-funded project described here, our design aims were extended to ensure compatibility between the sources. Such compatibility will mean that the current DOE-funded facility can be retro-fitted with any upgraded features of the new proposed source. For example, one possibility to increase X-ray output is to use a rotating anode, capable of withstanding higher electron beam currents. We did not incorporate this into the current design as we could not be certain that it would meet required specifications. However, we will endeavour to develop such a target in the future (as part of the new proposal) and if successful, will fit it to this source. Similarly, the future source will exploit many aspects successfully developed for the DOE-funded source, such as its modular design, the electron gun design and many of the beam alignment methods.

\section{Methods}

\section{Microfocus Source Design}

Aspects of the development of the microfocus source are described in $[8,9]$. The development of the source is also the subject of a $\mathrm{PhD}$ thesis recently submitted by Kirk Atkinson. [10]. A cutaway view of the source is depicted in figures 2 and 3. ZP diffractive optics are used to micro-focus characteristic-K X-rays, generated by the focussed electron bombardment of a target. The X-ray source comprises of two standard 6-way 'vacuum cubes', with sides $114 \mathrm{~mm}$ and with each face machined to accept DN63 CF 'Conflat' vacuum fittings. One cube is fitted with the electron gun, while the other supports the target and X-ray focussing assembly. Originally, the cubes were separated by a gate-valve to allow each cube to be vacuum-isolated. However, this was eventually removed, as it greatly increased the difficulty in achieving a precise mechanical alignment between the two cubes. The cubes are now joined by a $125 \mathrm{~mm}$ long custom-built mid-section, to which is mounted the electron gun anode and aperture, two sets of scan coils and the electron focussing magnet. The advantage of this is that the all the important electron-optical components are mounted on one assembly that can be laser-aligned offline, prior to assembly. Each cube is pumped by its own turbo-molecular pump that drops though a hole in $1 \mathrm{~m}$ by $1.5 \mathrm{~m}$ optical table on which the source is mounted. 
The source is supported by linear bearings so that it can be aligned with the microscope and sample stage. Separate gauges are used to monitor the vacuum in each cube, which is typically $10^{-7} \mathrm{mbar}$, or better.

The electron focussing system, including the gun assembly and the focussing assembly were developed using finite-element analysis calculations. The electron gun is custom-built, fitted with a high-brightness lanthanum hexaboride cathode (Kimball, USA) and designed to operate up to $15 \mathrm{kV}$. The gun is mechanically decoupled from its vacuum cube by a 'pan and tilt' positioning device, such that it can be precisely aligned with the anode. A number of gun-anode geometries have been tested; the most satisfactory with regard to ease of alignment and electron beam spot definition is the so-called Pierce-gun arrangement. Electron beam transport to the focussing magnet is optimised by the two sets of scan coils mounted to the mid-section. They allow for modest 'dog-legging' of the beam to correct any minor mechanical mis-alignments. The electrons are focused onto a target using a permanent neodymium-iron-boron magnet assembly. The design of the magnet is loosely based on a proposed design for a portable scanning electron microscopy system [11]. The final design was developed using FEA, as shown in figure 4. The unusual approach of using a permanent magnet has the advantage that no power supply is necessary, as would be the case if electromagnetic focussing were used. However, as the magnet strength is fixed, focussing onto the target has to be achieved by other means. In this system, it is accomplished by fine-tuning the target position via a vacuum position feedthrough.

All power supplies and controls for the electron gun, the scan coils and source controls are housed in a single cabinet located below the optical bench. Also in the cabinet are the power supplies and controls for the vacuum pumps. These are interlocked with the source power supplies to prevent or terminate operation of the source if inappropriate vacuum conditions exist.

\section{The X-ray focussing Assembly}

A detailed view of the $\mathrm{X}$-ray focussing assembly is shown in figure 3. The X-rays are focussed using ZP diffractive optics. The ZP is mounted in an assembly at the end of a $10 \mathrm{~mm}$ diameter hollow vertical shaft above the X-ray producing target. Between the target and the entrance to the shaft is an adjustable mirror that reflects the X-rays at grazing incidence (between 2-3 degrees). The mirror serves to remove unwanted Bremsstrahlung radiation at higher energies, which would otherwise be incorrectly focused (the focal length of the ZP is energy dependant). Alignment of the shaft requires two mechanical degrees of freedom, operable while the source is under vacuum and energised. First is a tilt mechanism that sets the mirror angle and second is translation of the whole ZP assembly, including the mirror and shaft. This is to keep the ZP correctly positioned as the mirror is tilted. When correctly aligned, the X-rays emerge vertically upward through a $0.5 \mathrm{~mm}$ square silicon nitride window, $100 \mathrm{~nm}$ thick (Silson Ltd, UK). The ZP is mounted directly above this and a 3-axis adjustable order-selecting aperture (OSA) is mounted above the ZP. The OSA is needed to remove unwanted orders of X-rays diffracted by the ZP. The arrangement is shown schematically in figure 5. To be effective, the OSA has to be small (typically, a $10 \mu \mathrm{m}$ diameter aperture), therefore it must be precisely aligned and secured in $\mathrm{X}, \mathrm{Y}$ and $\mathrm{Z}$ axis directions. The OSA is aligned horizontally by manipulation of opposing screws that move a $25 \mathrm{~mm}$ diameter two-part cylindrical assembly that supports the OSA on an end-cap. The two parts of the cylinder screw into each other and can be locked in position, providing the necessary motion to align the OSA vertically. The enclosed volume within the cylindrical OSA mount is flushed with helium to reduce the attenuation of the X-rays. Delivery of X-rays to the sample is controlled by means of a small solenoid operated shutter just above the ZP and within the OSA mount (not shown in figure 3 ).

\section{Automated Microirradiation and Source Control}

The cell finding microscopy system and positioning stage is custom designed and built, but uses critical parts from an epi-fluorescence microscope (Nikon, Japan) and a closed-loop, 3-axis cell positioning stage (Mazhauser, SCAN-100 Germany), The microscopy system is mounted on the optical table and is shown in figure 6 . The whole microscope/stage assembly is supported by two vertically mounted linear bearings such that it can be precisely raised or lowered, to cater for large differences in the focal length of the X-ray ZPs (this is more easily seen in figure 22). Typically, focal lengths from $5 \mathrm{~mm}$ to $100 \mathrm{~mm}$ are readily accommodated. Additionally, the vertical bearings are supported on $90 \mathrm{~mm}$ square extruded columns that could easily be lengthened if longer focal lengths are needed. It has been designed this way to allow other $\mathrm{X}$-ray optical devices (with longer focal lengths) to be used in the future. For example, our current involvement in the development of novel 'smart' X-ray optics will hopefully yield new focussing systems that can be retro-fitted to the source.

A number of mechanical actions are built into the microscope assembly to achieve the required alignments. Vertical motorised micro-positioning of the microscope objective turret allows the focus of the microscope 
and the X-ray focus to coincide in space (i.e. at the point where the cell should be positioned for exposure). The stage is also mounted on a motorised assembly to precisely raise or lower the cell dish to the correct height. A cell is aligned for irradiation by locating it a few tens of microns directly above the OSA and in focus optically, as seen through the microscope (having previously aligned the microscope focus to the X-ray focus). As with our other microbeam facilities, we have developed software that can automatically identify and align targets to the source. However, much improved procedures have been implemented, taking advantage of the dramatic improvement in PC processing power since the earlier facilities were developed. The new software has been developed in $\mathrm{C}$ and $\mathrm{C}++$ programming languages and operates through National Instruments CVI LabWindows software. In addition to cell imaging and alignment, the software controls and monitors all key aspects of the operation of the source. Figure 7 shows the PC controls for operation of the source. Many other software panels are available for various aspects of source control and monitoring. Control is implanted through an expandable bus, based on the use of the $\mathrm{I}^{2} \mathrm{C}$ bus, itself controlled through a single USB connection to the PC. This allows the addition of further devices as future developments, not part of the initial design, are implemented.

Cells are supported on $0.9 \mu \mathrm{m}$ thick Mylar that forms the base of a cell dish, using an established design [12]. The cell imaging method uses widefield fluorescence microscopy, with a 40X. 0.9 NA water-immersion objective, giving a diffraction-limited image over a $220 \times 290 \mu \mathrm{m}$ field of view. 'Image stitching' is used to define a map of all cells across the dish. A number of image processing algorithms for identifying cells are implemented, including a modified Hough Transform (called CHARM: Compact Hough transform and Radial Map) that is well suited to distinguishing cell-like objects and insensitive to minor focus variations. The software control and imaging is described fully in [13].

\section{Beam Detection and Diagnostics}

A range of X-ray detection and diagnostic tools have been acquired or developed specifically for the facility. To check the alignment of the electron beam gun and electron optical components, a phosphor screen is installed in place of the target assembly and the glow from the incident electron beam is imaged through a temporary glass viewport. The screen is positioned at a number of locations beyond the electron beam focus to establish the symmetry and divergence of the electron beam. A symmetrical spot will be seen only when all the electron optical components are properly aligned. The electron beam profile has been further analysed using knife-edge scans through the beam, primarily to confirm that the focussing action of the final magnet assembly performs as predicted by the FEA. To enable the alignment of the X-ray producing target with the focus of the electron beam, a custom built microscope is used to image the focussed electron beam on the target, through a vacuum window on the side of the cube. When the target is correctly aligned, the power density will be at its maximum and the imaged spot will be bright.

The primary method for measuring the X-ray intensity at the irradiation position is to use a custom-built proportional counter with a $0.9 \mu \mathrm{m}$ Mylar window and continuously flushed with an argon/methane mix at atmospheric pressure. This is shown in figure 8. A standalone power supply for the counter and a charge to pulse-height amplifier has also been developed. The counter is typically operated at a voltage of $1900 \mathrm{~V}$ and the signal from the amplifier is fed to a multi-channel analyser (MCA, MCA8000A, Amptek, USA) such that low-resolution energy spectra can be acquired. In normal use, the counter is fitted to one of the available locations on the microscope objective turret (see figure 9). For this reason, the counter has been designed to about the same size and to have the same working-distance as the objectives, such that it can be readily located, simply by selecting that turret position. Note that the turret is motorised and turret positions can be selected under PC control.

For X-rays other than $\mathrm{C}_{\mathrm{K}}$, a cooled Si-PIN photodiode (XR-C100, Amptek, USA) fitted with a beryllium window is used. The detector has a $150 \mathrm{eV}$ FWHM energy resolution, but is ineffective below $1 \mathrm{keV}$. However, it is useful for measuring $\mathrm{Al}_{\mathrm{K}}$ and $\mathrm{Ti}_{\mathrm{K}} \mathrm{X}$-ray output as the detector has a high (and known) efficiency. It is somewhat fragile for routine use, so the detector is used to cross-calibrate the proportional counter. The counter has a reduced efficiency at higher energies $\left(41 \%\right.$ for $\mathrm{Al}_{\mathrm{K}}$ and $23 \%$ for $\left.\mathrm{Ti}_{\mathrm{K}}\right)$, but can be corrected for using the photodiode.

One further method used to analyse the focussed X-ray spot is through the use of radiochromic film. This film, which is relatively insensitive to daylight and requires no chemical processing is straightforward to use, but with a grain-size of several microns, cannot resolve very small spot sizes.

\section{Development issues and design priorities.}

One aspect of the source development that was the subject of a substantial 'rethink' as work progressed was the user interface and 'ease of operation'. Although not a key part of the original design specification, 
considerable effort was put into making the source operable without the need for complex start-up and alignment procedures. A number of factors made this a key priority, not least being the imminent relocation of GCI and its scientists to various locations Worldwide. The proposal for the relocation of GCI emerged after the start of the project and resulted in a number of key scientists moving, or planning to move to new (and different) institutes. In particular, Dr Prise (the principle end-user of the facility) will move to another Institute and it is planned that he will take the facility with him. It became essential therefore that the source be a robust, standalone facility with, as far as possible, a straightforward 'turnkey' operation. It should be noted that Dr Schettino also moved to another Institute a key moment in the source development. Dr Schettino was to be primarily responsible for the design and development of the X-ray focussing assembly, but left at an early stage in its development. Although his departure was a setback, we have nevertheless designed and built an X-ray focussing assembly based on Dr Schettino's preliminary ideas. It should also be noted the Dr Schettino has recently re-joined Dr Prise's new group and will have a primary responsibility for the future development and use of the facility.

\section{Results and Discussion}

\section{Alignment of Electron Beam Optics}

Figure 10 shows the beam profile measured using a knife-edge scan at the target position, but without the focussing magnet installed. The graph shows that the divergence of the beam is reduced by fitting a $0.65 \mathrm{~mm}$ diameter aperture about $25 \mathrm{~mm}$ beyond the anode. The FWHM beam diameter is just over $1 \mathrm{~mm}$, which is reasonably within the acceptance area of the focussing magnet (which has a $3 \mathrm{~mm}$ aperture at the tip).

Accurate alignment of the anode, aperture and focussing magnet is achieved using a laser prior to assembly of the source. Once assembled, the electron gun can be aligned to the anode using opposing set-screws. To facilitate movement, the gun is mounted on flexible vacuum bellows. With the phosphor screen mounted a few millimetres beyond the electron beam focus, the source is energised and a bright spot is seen on the screen. The gun position is then adjusted until a symmetrical spot is achieved. This condition is shown in figure 11. In the image, the screen is $25 \mathrm{~mm}$ square, so the spot is just a few millimetres diameter. This shows, as expected, that the beam diverges beyond the electron beam focus.

Once the beam is aligned, the target is installed. A micrometer screw can adjust the target position along the axis of the electron beam. To achieve the correct alignment, the bright spot generated by the incident focussed electrons is observed though a viewport. Figure 12 shows the appearance of the spot when focussed. Note that flare in the camera makes the spot appear larger that actuality. To critically align the target, the spot is viewed through the viewport using a custom-built microscope. A typical image acquired using the microscope is shown in figure 13 for a $10 \mathrm{kV}, 0.16 \mathrm{~mA}$ electron beam. From the image, the electron beam spot size is estimated to be about 10-15 $\mu \mathrm{m}$ diameter, assuming the pattern of heat observed reflects the electron beam distribution. By eye, it is evident that the spot may actually be smaller that this, as again, flare in the imaging system can make the spot appear larger.

The X-ray output of the source is dependant of the electron beam current incident on the target and the accelerating voltage. The electron beam current leaving the cathode as a function of accelerating voltage and cathode heater current is shown in figure 14. Note that when properly aligned, the electron beam current incident on the target is $\sim 70-80 \%$ of the current leaving the cathode. For long cathode lifetimes, the heater current is not operated beyond 2.2A. At the highest currents and voltages, up to $13 \mathrm{~W}$ can be deposited on the target. To cool the target, it is mounted on a copper shaft leading to a fan-cooled heat-sink. Currently, the source is not operated at the maximum operating conditions for extended periods, as it does heat up leading to some thermal expansion and changes in source alignment. Even at typical operating conditions $(10 \mathrm{kV}, 200-$ $500 \mu \mathrm{A}$ ) it is good practise to run the source for an hour to 'temperature stabilise' before making final alignment adjustments.

\section{The X-ray focussing assembly}

Critical features of the X-ray focussing assembly are shown in figure 15 . When generating carbon X-rays, it is necessary to remove unwanted bremsstrahlung radiation generated in the target, as it will be incorrectly focussed by the ZP. To do this the X-rays are first reflected off a planer mirror, set at grazing incidence, as depicted in figures 15 and 16. At the correct angle, the mirror reflects $\mathrm{C}_{\mathrm{K}} \mathrm{X}$-rays, but absorbs X-rays with higher energies (X-rays below $\mathrm{C}_{\mathrm{K}}$ energy are substantially absorbed). Figure 15 shows two alignment controls (for X-ray focussing assembly translation and mirror tilt) that allow the mirror to be properly aligned. The alignment is achieved by recording X-ray spectra as the mirror is adjusted. Correct alignment occurs at 2-3 degrees incident angle. Figure 17 shows the MCA spectra with 0 degrees (i.e. no mirror) and 2 degrees incident angle. It can be seen that there is a broad peak corresponding to $C_{K} X$-rays and a spread out 'peak' at higher energies ('channel' on the graph), which is the bremsstrahlung radiation. A full study of X-ray mirror 
properties is given in [7]. For $\mathrm{Al}_{\mathrm{K}}$ and $\mathrm{Ti}_{\mathrm{K}} \mathrm{X}$-rays, removal of bremsstrahlung radiation by a planer mirror is less efficient. In this case, we use multilayer mirrors which function as bandpass filters, specifically tuned to reflect the desired energy. These have been developed by the X-ray Microscopy Group at Kings College London. The X-rays exit the system through a $500 \mu \mathrm{m}$ square vacuum window made of $100 \mathrm{~nm}$ thick silicone nitride mounted $\sim 140 \mathrm{~mm}$ from the target. Once the mirror is aligned, the measured $\mathrm{C}_{\mathrm{K}} \mathrm{X}$-ray flux through the window as a function of the electron beam current on target is about 3000 photons s ${ }^{-1} \mu \mathrm{A}^{-1}$. This corresponds to about $1.5 \times 10^{6}$ photons $\mathrm{s}^{-1}$ at typical operating conditions for cell exposures $(\sim 500 \mu \mathrm{A})$.

\section{OSA Alignment}

A microscope is used to centre the zone plate $2 \mathrm{~mm}$ above the vacuum window. Different zone plates are used to focus the beam depending on the type of X-rays being produced. So far, all experiments have been performed using a $200 \mu \mathrm{m}$ diameter zone plate to focus $\mathrm{C}_{\mathrm{K}}$ X-rays and has an effective focal length of $9.4 \mathrm{~mm}$ (first order diffracted X-rays).

Critical to the operation of the source is the alignment of the order-selecting aperture (OSA) just below the focus of the ZP. The OSA is necessary to allow only first-order diffracted X-rays to reach the sample and we are currently using OSAs with diameters as small as $10 \mu \mathrm{m}$. To align the OSA, it is mounted to the 3-axis stage that would normally support the cell dish. Automated procedures can then be used to scan the OSA and search for the peak X-ray intensity. The concept is shown in figure 18. After setting the correct height for the OSA (using the microscope establish the correct ZP-OSA distance, based on the known working distance of the $\mathrm{ZP}$ ), the stage is moved initially in $25 \mu \mathrm{m}$ steps, in a $2 \mathrm{D}$ spiral path, beginning at a position determined geometrically to be close to optimum alignment of the zone plate and OSA. Using automated procedures, the stage pauses briefly at every step and the number of counts per second is logged. The end result is a map of dose rate for a predetermined region around the starting point. With this coarse stage movement of $25 \mu \mathrm{m}$, we found just one position where the dose rate was significantly higher than neighbouring positions. It can therefore be assumed that the first order focus lies entirely within this region. Next, the process is repeated using finer $10 \mu \mathrm{m}$ steps, beginning at the peak position found previously. In this instance, a region of high dose rate is found. Notably, the transition between high dose rates and low dose rates occurs within one $10 \mu \mathrm{m}$ step which indicates that the actual focus spot is much less than the size of the $50 \mu \mathrm{m}$ OSA. Next, we replace the $50 \mu \mathrm{m}$ OSA with a $10 \mu \mathrm{m}$ OSA. The stage is moved until the smaller OSA is at the centre of the peak area found in the previous measurements. Again, the measurements are repeated, this time moving the stage in increments of $2 \mu \mathrm{m}$. Once the correct OSA position is this is established, the microscope is used to image the OSA and log its position in space precisely. It is then decoupled from the microscope stage and supported on its adjustable mount that is part of the ZP assembly, using the logged microscope position to achieve the correct location.

Figure 19 shows part of a series of scans depicting the number of counts per second after the X-ray beam has exited the OSA. This figure shows three results from a set of seven scans. The scans were recorded with a vertical spacing of $50 \mu \mathrm{m}$ between each one. An infinitesimally small spot would produce a flat-topped spot with vertical sides. In practise, the correct height for the OSA corresponds to the scan that most closely meets this criterion. In the example shown in figure 19, the second scan shows that the focussed spot size is less than the $2 \mu \mathrm{m}$ step size and that this is the best alignment for the OSA. Details of the alignment and performance of the ZP assembly are given in [14].

The estimated spot size has been verified using radiochromic film. Figure 20 shows a series of exposures of the focussed $\mathrm{C}_{\mathrm{K}}$ stop at different OSA heights. It can be seen that as the correct focus is approached, the spot size diminishes. Note that this is more evident when viewed by eye through a microscope than can be reproduced in the image. The image confirms that the smallest focussed spot size is about $2 \mu \mathrm{m}$.

\section{Dose rate and $X$-ray energy}

A number of factors determine the X-ray dose rate, including the size and efficiency of the zone plate. We have not yet realized the full potential of the source as we are currently using 'old' ZPs even though we have specified, ordered and received much better ZPs. For reasons that are explained below, we are delaying the fitting of our high efficiency ZPs. Using an existing $200 \mu \mathrm{m}$ diameter $\mathrm{ZP}$, the measured $\mathrm{C}_{\mathrm{K}} \mathrm{X}$-ray count rate at electron beam settings of $10 \mathrm{kV}$ and $300 \mu \mathrm{A}$ is 3000 counts s${ }^{-1}$ at the sample position. This is equivalent to about $0.3 \mathrm{~Gy} \mathrm{~s}^{-1}$ in a typical V79 mammalian cell, based on a non-standard definition of dose (i.e. the energy deposited in the cell nucleus divided by the mass of the nucleus, a quantity sometimes referred as 'specific dose'). Note that this definition of dose is dependent both on the thickness of the cell and the cell's mass and is an inexact quantity for this reason. It is still a matter of conjecture as to what quantity should be used to define 'dose' in microbeam experiments. This dose rate is adequate for our current experimental programme. 
Nevertheless, we can be confident that with our new ZP fitted, the dose rate will be significantly improved. Our new ZP has a diameter of $500 \mu \mathrm{m}$ and a working distance of $25 \mathrm{~mm}$ and has a calculated 2.8 -fold increase is first-order focus efficiency. In addition, operating the cathode at full power (2.2A heater current) will yield a 2 -fold increase in output (but reduce cathode lifetimes). Thus, we can expect cell dose rates approaching $1.7 \mathrm{~Gy} \mathrm{~s}^{-1}$, if required.

One of the design aims of the project was to allow energies other than $0.278 \mathrm{keV} \mathrm{C}_{\mathrm{K}} \mathrm{X}$-rays to be used. While the source is now operable using a range of $\mathrm{X}$-ray energies, we have concentrated on its capability as a source of focussed $\mathrm{C}_{\mathrm{K}} \mathrm{X}$-rays until we are completely satisfied with the performance of the source (for example, we are aware of some design weaknesses in the ZP alignment system that we are currently rectifying; see next section). For this reason, we have not yet measured the performance of the source with $\mathrm{Al}_{\mathrm{K}}$ and $\mathrm{Ti}_{\mathrm{K}} \mathrm{ZPs}$ installed, although we have developed interchangeable targets and have measured the X-ray outputs using these targets. Figure 21 shows the measured X-ray outputs without a ZP as a function of target current for $\mathrm{C}_{\mathrm{K}}$, $\mathrm{A}_{\mathrm{K}}$ (at $10 \mathrm{keV}$ electron beam energy) and $\mathrm{Ti}_{\mathrm{K}}$ (for three electron beam energies). The data were measured using the proportional counter and after correction for the counter efficiency, the count rate are for $\mathrm{C}_{\mathrm{K}}(10 \mathrm{keV}$ electron beam) is $4.4 \times 10^{3}$ counts s $\mathrm{s}^{-1} \mu \mathrm{A}^{-1} \mathrm{~mm}^{-2}$, for $\mathrm{Al}_{\mathrm{K}} \quad(10 \mathrm{keV}$ electron beam $)$ is $4.0 \times 10^{3}$ counts $\mathrm{s}^{-1} \mu \mathrm{A}^{-1} \mathrm{~mm}^{-2}$ and for $\mathrm{Ti}_{\mathrm{K}}\left(13 \mathrm{keV}\right.$ electron beam) is $2.2 \times 10^{3}$ counts s $\mathrm{s}^{-1} \mu \mathrm{A}^{-1} \mathrm{~mm}^{-2}$. In all cases, the X-rays are monochromated using either the grazing-incidence planar mirror $\left(\mathrm{C}_{\mathrm{K}} \mathrm{X}\right.$-rays $)$ or a multi-layer mirror $\left(\mathrm{Al}_{\mathrm{K}}, \mathrm{Ti}_{\mathrm{K}} \mathrm{X}\right.$-rays). The measurements were taken $10 \mathrm{~mm}$ from the exit window, with the gap flushed with helium. The helium will attenuate the $\mathrm{C}_{\mathrm{K}} \mathrm{X}$-rays by $\mathrm{x} 0.58$, but this is close to the typical focal length of a $\mathrm{C}_{\mathrm{K}} \mathrm{ZP}$, so reasonably represents the actual attenuation by helium when a ZP is fitted. For the higher energy $\mathrm{X}$-rays, the attenuation due to the helium path is small. Most notable of these data is that for the $\mathrm{Ti}_{\mathrm{K}} \mathrm{X}$-rays, where the output of our original source required $>10$ second exposures to deliver about 1 Gy to a cell. At a high, but acceptable accelerating voltage and beam current $(13 \mathrm{keV}, 450 \mu \mathrm{A})$, the measured X-ray output is about $10^{6}$ counts $\mathrm{s}^{-1} \mathrm{~mm}^{-2}$. This improves on the output of our original source by a factor of $\times 2.1$. It should also be noted that the original system was not monochromated and therefore this is not an accurate comparison. In reality, the improvement is even greater. This is a worthwhile gain in reduced exposure time and improved beam quality. Similar gains for $\mathrm{C}_{\mathrm{K}}$ and $\mathrm{AL}_{\mathrm{K}}$ outputs are also seen. Further significant improvements are being sought by increasing the heat dissipation within the target (which is now the dose-limiting factor).

To change to a different energy requires that we swap targets (from a carbon target to either an aluminium or a titanium target). In addition, the appropriate ZP and mirror must be fitted and the OSA re-aligned and the microscope position adjusted to accommodate the change in ZP focal length. On the new system, target swapping is now straightforward, taking just a few minutes. Also, as required, re-configuring the ZP assembly is now quicker, than on the original system. However, it is still a lengthy process to then align the mirror, then align the OSA to the ZP, so the eventual plan is to make the whole ZP assembly interchangeable.

With regard to changing energy, it should be noted that one of the key improvements over our old X-ray probe is the mechanical alignment system for raising microscope. This is necessary when swapping between X-ray energies as the ZPs can have significantly different working distances. By having the whole system on adjustable vertical rails, it now takes just minutes to reconfigure the microscope. In the past, this would require several days of disassembly and reassembly. The arrangement for raising and lowering the microscope is shown in figure 22 .

\section{Current Status and Future Plans}

As a result of this US DOE-funded project, we have been successful in designing and building a versatile, standalone X-ray microprobe that will underpin UK research using X-ray micro-irradiation techniques. While the source is a fully developed facility, clearly some of the design aims, while implemented, have yet to be thoroughly tested and exploited, due partly to several confounding factors that arose during the development of the source. As already mentioned, the imminent closure of GCI at its current location, coupled with the restructuring and break-up of the established 'microbeam group' at GCI had a significant impact on the development of the source. However, the facility has become a major focus for the continued collaboration of most of the key scientists involved in this work. It is now known that Dr Prise will lead a new Group based at Belfast (to be joined by Dr Schettino) while Prof Folkard and Prof Vojnovic will be based at the new Institute Radiation Oncology and Biology Institute being formed at Oxford. The microfocus source will be relocated at Belfast and be further developed (through collaboration) as a key part of Dr Prise's research programme. But without the original established team sited at Belfast, priority has been given to developing a robust, standalone facility that is as straightforward as possible to operate and requiring minimal technical support. This has been largely achieved, although there are aspects of its operation that we are improving still (see below). We have yet to test its use as a multi-target microprobe, as we have given highest priority to 
developing and testing the other aspects of its operation (such as the microscopy) and to ensuring first that all operational aspects of the source function properly and reliably without the need for routine technical support.

As with any project of this size and complexity, development is a continuous process. We expect the source to have long future as improvements are sought and implemented and new developments arise. In the short term, we are already developing a new ZP assembly. While the design described here is fully operative, routine use has highlighted areas where the setting up processes could be simplified. In particular, the critical step of aligning the OSA requires some skill and a steady hand (although the automated setup procedures improve considerably on our original design). It has become evident that the design could be dramatically simplified if the shutter were to be relocated away from the ZP assembly. In the latest design, the shutter is sited in the body of the target assembly and a much smaller OSA mount is now supported on a miniature precision 3-axis stage (National Apertures Inc., USA). Figure 23 shows the new assembly. Additionally, we have developed new methods for mounting and demounting ZPs, without the need for glues. The cost of ZPs has increased dramatically recently, so we believe that devising a method for mounting these fragile and expensive items with minimal risk of breakage is a high priority. This is one reason for delaying the testing of our new $\mathrm{C}_{\mathrm{K}} \mathrm{ZPs}$ or our $\mathrm{Al}_{\mathrm{K}}$ and $\mathrm{Ti}_{\mathrm{K}} \mathrm{ZPs}$; we want to first construct the improved mount as part of the new $\mathrm{ZP}$ assembly.

The other aspect which we expect to yield significant improvements in the longer term is the development of new X-ray focussing methods that are significantly more efficient. Of particular interest is the use of microstructured optical arrays (MOAs, similar in concept to polycapillary and microchannel plate optics) which use grazing incidence reflection through consecutive aligned arrays of channels. The fabrication of MOAs is a key part of a recently awarded grant to a joint consortium (including GCI) to develop and exploit new 'smart' X-ray optics. The particular advantage of MOAs is that they have a high efficiency up to and beyond $\mathrm{Ti}_{\mathrm{K}}$ energies. They are also achromatic and therefore can make use of the Bremsstrahlung radiation produced by the source.

\section{Acknowledgments}

The development of the microprobe has involved major contributions from a number of GCI scientists, including P. Barber, R.J. Locke and R.G. Pierce for their work on software development. S. Gilchrist, G. Flaccavento and R. Newman for work on instrumentation development and testing. Also thanks go to Y. El-Taha, who successfully completed an MSc project in connection with the source. Thanks must be given for the support of Cancer Research-UK.

\section{References}

1. SCHETTINO G., FOLKARD M., MICHAEL B.D. and PRISE K.M., 2005, Low-dose binary behaviour of bystander cell killing after microbeam irradiation of a single cell with focused C(k) x rays. Radiat Res.,163, 332-336.

2. FOLKARD M., PRISE K.M., SCHETTINO G., SHAO C., GILCHRIST S. and VOJNOVIC B., 2005, New insights into the cellular response to radiation using microbeams, Nucl. Instr. Meth. in Phys. Res., 231, 189-194

3. SHAO, C., FOLKARD, M., MICHAEL, B.D and PRISE, K.M., 2005, Bystander signalling between glioma cells and fibroblasts targeted with counted particles. Int. J. Cancer., 116, 45-51.

4. PRISE, K.M., FOLKARD, M. and MICHAEL, B.D. 2003, A review of the bystander effect and its implications for lowdose exposure. Radiat Prot. Dosimetry, 104, 347-355.

5. FOLKARD, M., PRISE, K. M., VOJNOVIC, B., GILCHRIST, S., SCHETTINO, G., BELYAKOV, O. V., OZOLS, A. and MICHAEL, B. D. 2001, The impact of microbeams in radiation biology. Nucl. Instr. Meth. in Phys. Res. B 181 426-430.

6. FOlKard, M., VOJnOViC, B., PRISE, K. M., ATKInSON, K., SCHETTINO, G., MiCHETTE, A. G., GILCHRIST, S., SUNDERLAND, R. and MICHAEL, B. D., 2004. The future of the GCI microbeams. Radiat. Res., $161,88-89$.

7. FOLKARD, M, SCHETTINO, G, VOJNOVIC, B, GILCHRIST, S, MICHETTE, A.G., PFAUNTSCH, S. J., PRISE K. M. and MICHAEL, B.D. 2001, A focused soft X-ray microbeam for targeting cells individually with submicrometer accuracy. Radiat. Res. 156, 796-804.

8. FOLKARD, M., ATKINSON, K., FLACCAVENTO, G., BARBER, P.R., LOCKE, R.J., PIERCE, R.G., GILCHRIST, S, MICHETTE, A.G., PRISE K. M. and VOJNOVIC, B., 2006, Development of the GCI multitarget X-ray microprobe. Radiat. Res. 166, 659-660.

9. ATKINSON, K.D., FOLKARD, M., VOJNOVIC, B., SCHETTINO, G., PRISE, K.M., MICHAEL, B.D. and MICHETTE, A.G., 2004, Developing a laboratory-based titanium Ka X-ray microprobe. Radiat. Res. 161, $103-104$.

10. ATKINSON, K.D., 2007, An improved soft X-ray microprobe for irradiating sub-cellular targets. PhD thesis, submitted 2006 (Kings College, London, UK). 
11. KHURSHEED, A., PHANG J.C., and THONG, J.T.L., 1998 A portable scanning electron microscope column design based on the use of permanent magnets. Scanning 20, 87-91.

12. FOLKARD, M., VOJNOVIC, B., PRISE, K.M., BOWEY, A.G., LOCKE, R.J. SHETTINO, G. AND MICHAEL, B.D., 1997, A charged particle microbeam: I. Development of an experimental system for targeting cells individually with counted particles. Int. J. Radiat. Biol., 72, 375-385.

13. BARBER, P.R., LOCKE, R.J., PIERCE, R.G., NEWMAN, R.G., FOLKARD, M., and VOJNOVIC, B., 2006, The GCI multitarget X-ray microprobe: imaging, control and software automation. Radiat. Res. 166, 663-664.

14. FlaCCAVENTO, G., ATKINSON, K., BARBER, P.R., LOCKE, R.J., PIERCE, R.G., GILCHRIST, S, MICHETTE, A.G., PRISE K. M., VOJNOVIC, B. and FOLKARD, M., 2006, Performance of the GCI multitarget $\mathrm{X}$-ray microprobe. Radiat. Res. 166, 660-661. 


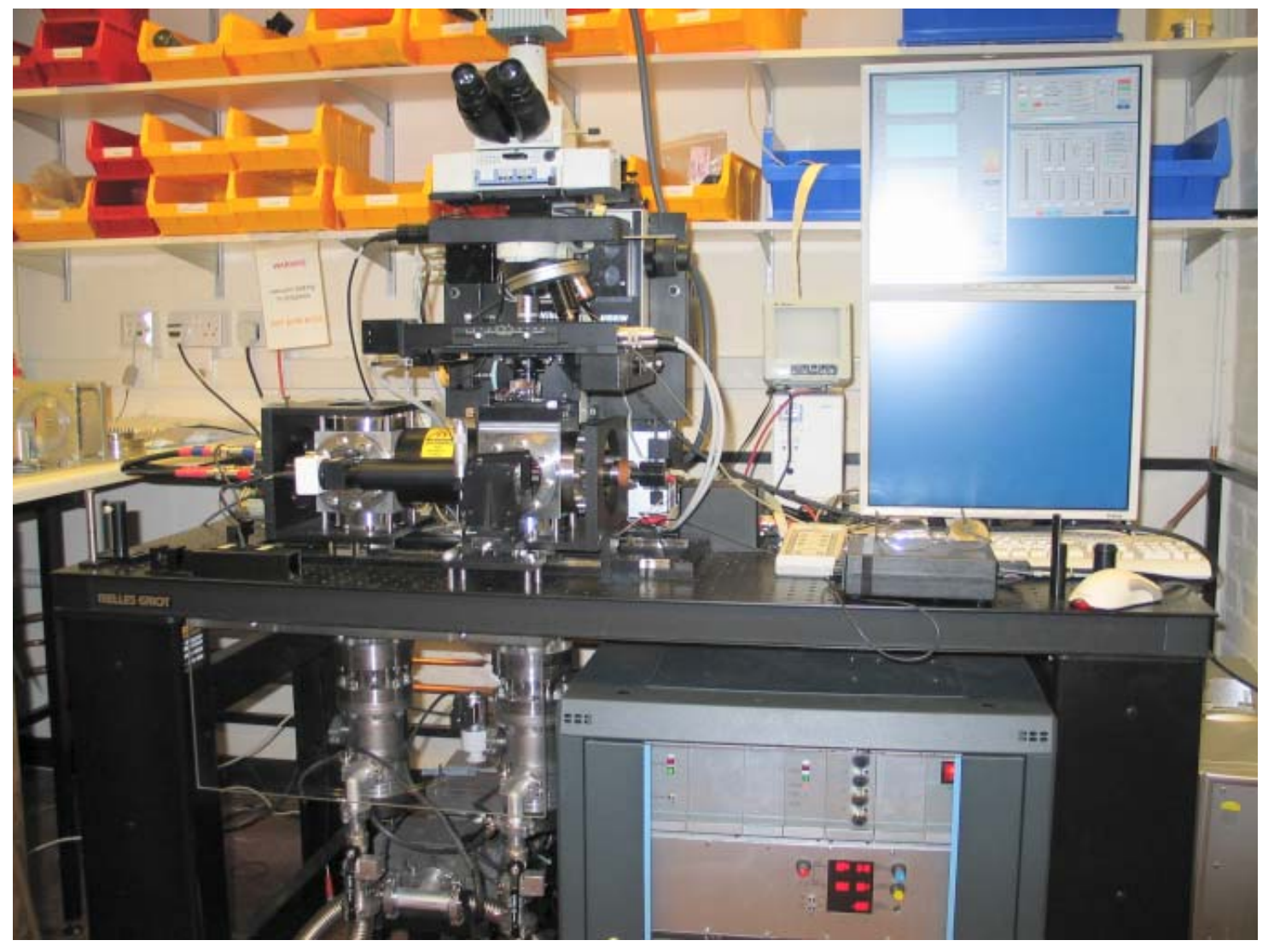

Figure 1. The X-ray microprobe 


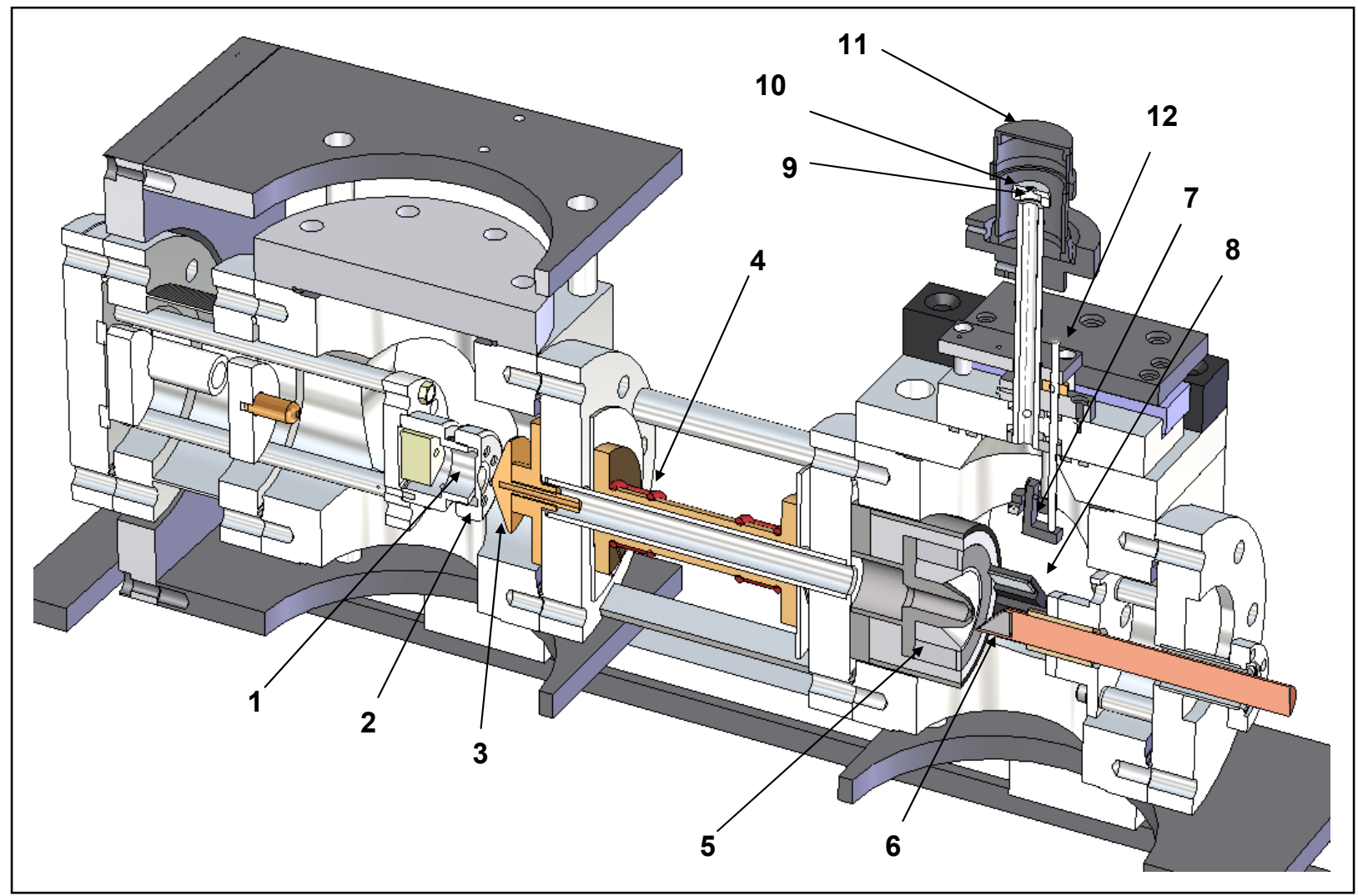

Figure 2. Cutaway view of source

$\begin{array}{cl}1 & \text { LAB filament location (filament not shown) } \\ 2 & \text { Grid } \\ 4 & \text { Anode } \\ 5 & \text { Scan coils } \\ 6 & \text { Electron focusing magnet } \\ 7 & \text { Target } \\ 8 & \text { X-ray grazing-incidence mirror (monochromator) } \\ 9 & \text { Optical mirror for viewing electron beam spot } \\ 10 & \text { Vacuum window } \\ 11 & \text { Zone-plate } \\ 12 & \text { Order-selecting aperture } \\ 13 & \text { Mirror tilt mechanism }\end{array}$




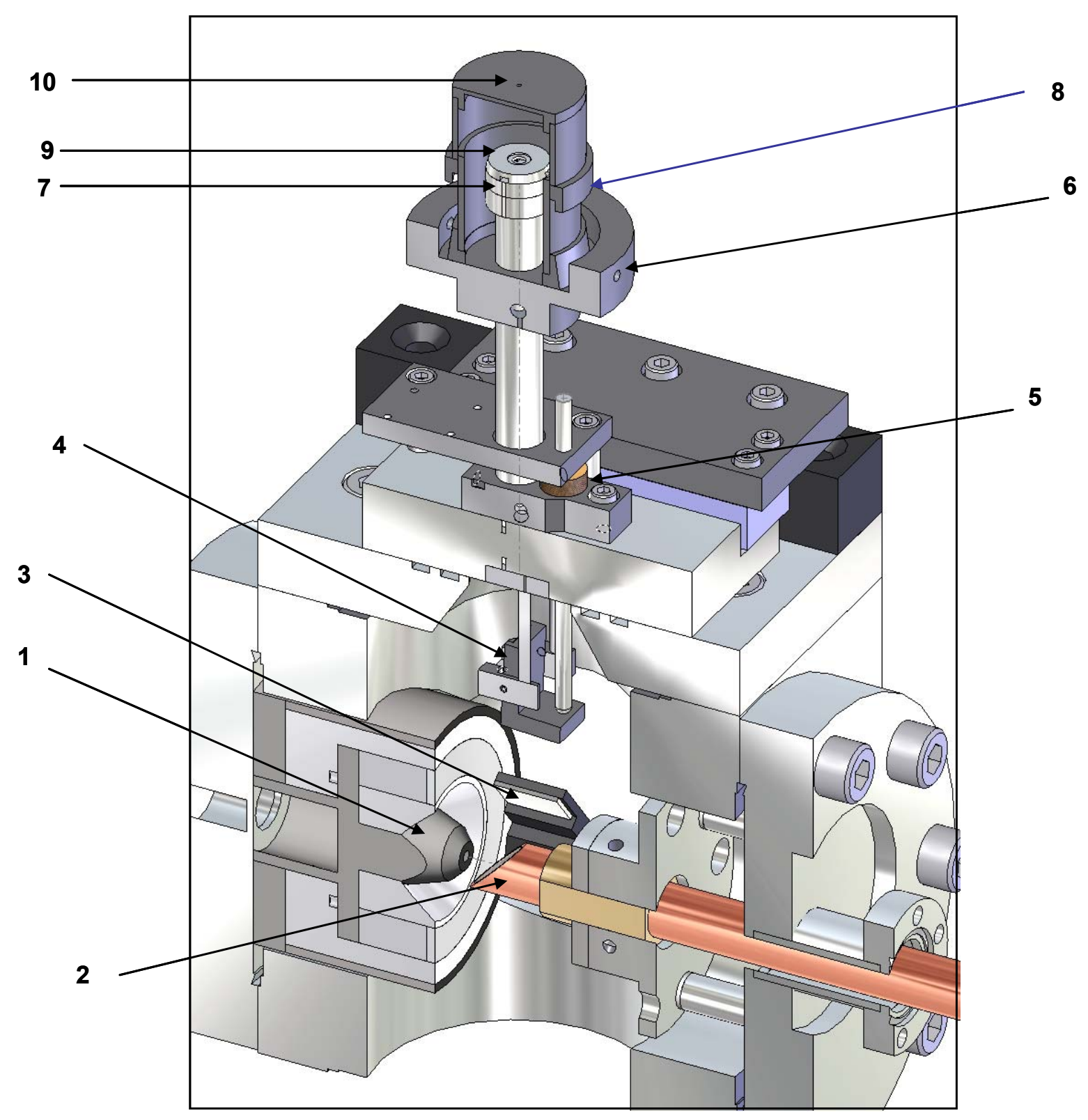

Figure 3. Close-up cutaway view of the target and zone plate assembly

1 Magnet

2 Copper shaft supporting target

3 Mirror for viewing electron beam spot on target

$4 \quad X$-ray grazing incidence mirror (monochromator)

5 Thumbwheel for setting mirror tilt

6 OSA static support

7 Vacuum window

8 OSA cylindrical moving support

9 Zone plate mount

10 Order-selecting aperture (OSA) 


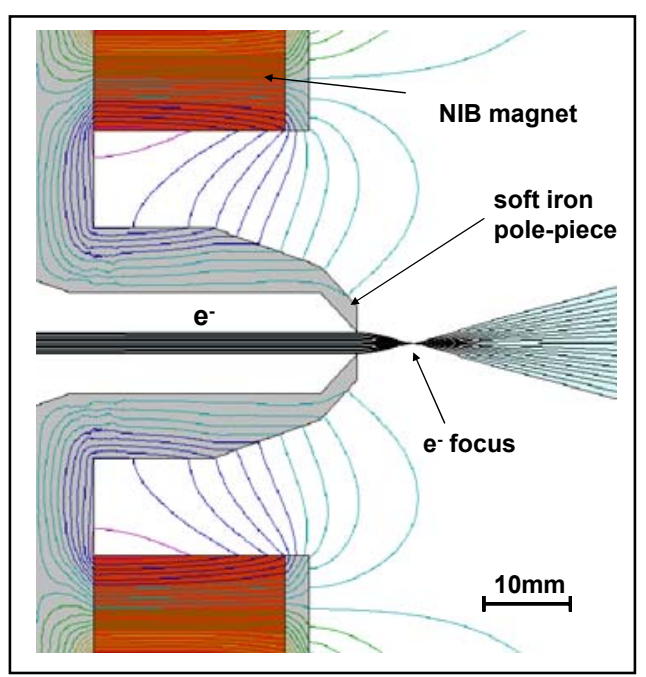

Figure 4: FEA model of the electron focussing lens

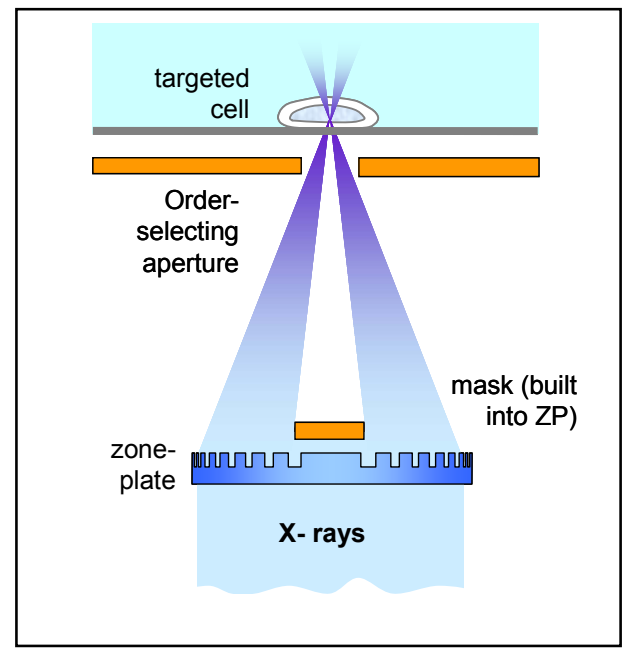

Figure 5: The focussing action of the zone plate (not to scale)

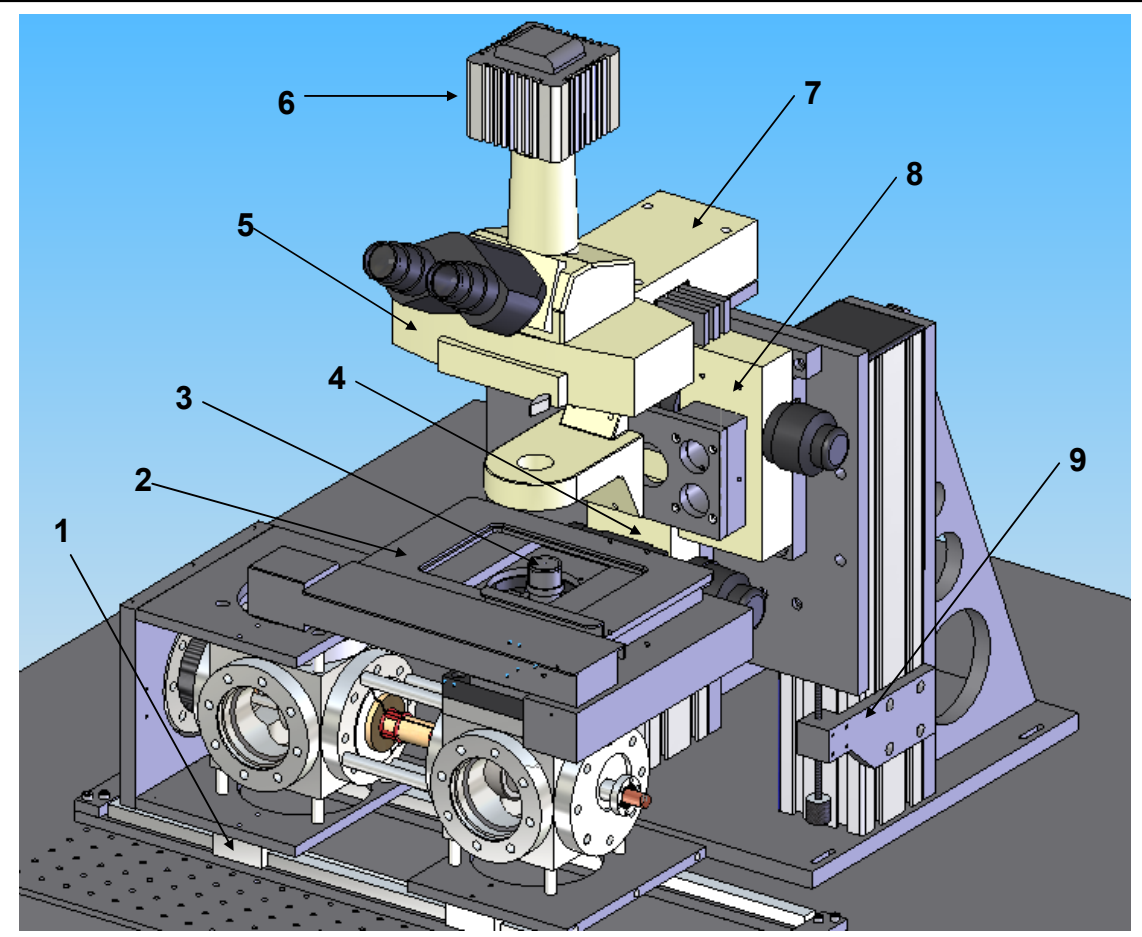

Figure 6 . The source and cell alignment system

Key:

$1 \quad$ Linear bearings supporting source

2 Marzhauser cell positioning stage

3 ZP assembly

4 Motorized stage Z-alignment

5 Filter cube assembly

6 CCD camera

$7 \quad$ Epi fluorescent light source

8 Motorized objective turret Z-alignment (turret not shown)

9 Microscope Z-aligner 


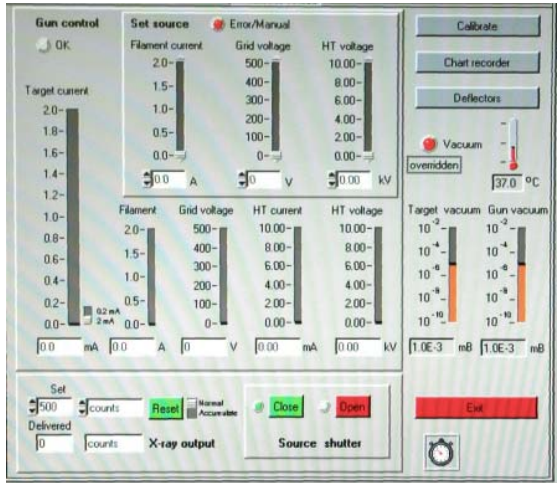

Figure 7: PC screenshot of the source control

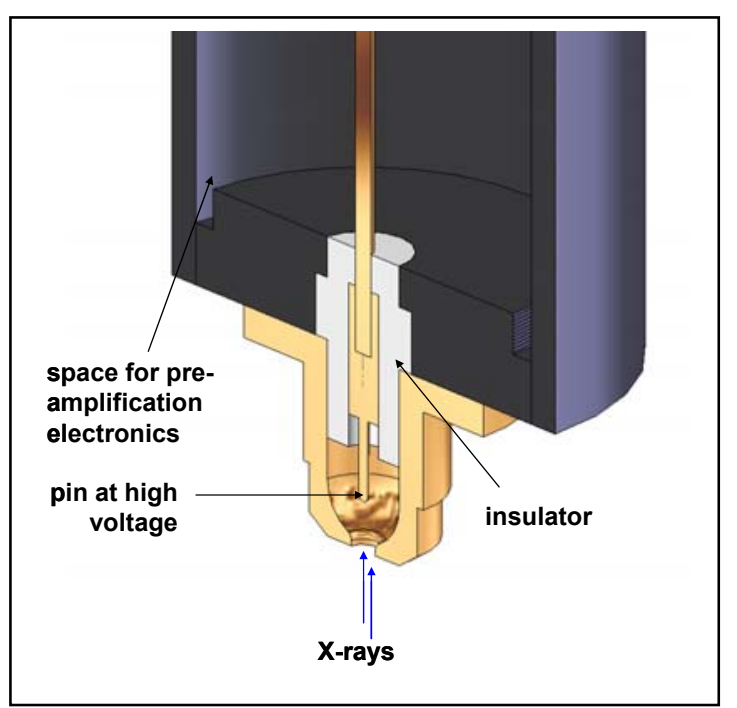

Figure 8: The X-ray proportional counter

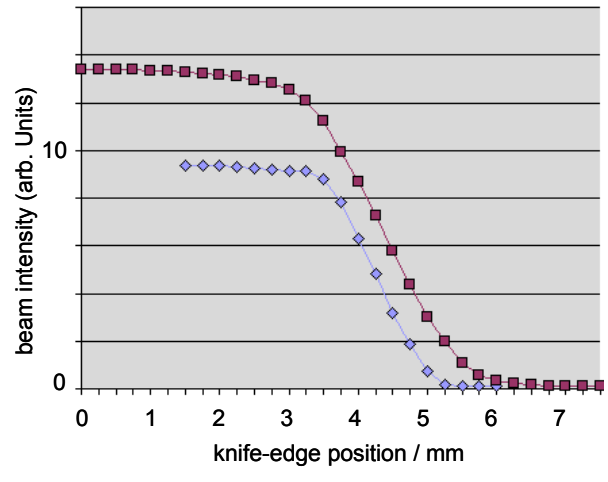

Figure 10: the beam profile at the target position, with (blue) and without (red) a pre-aperture.

Figure 9: The microscope turret, showing the proportional counter

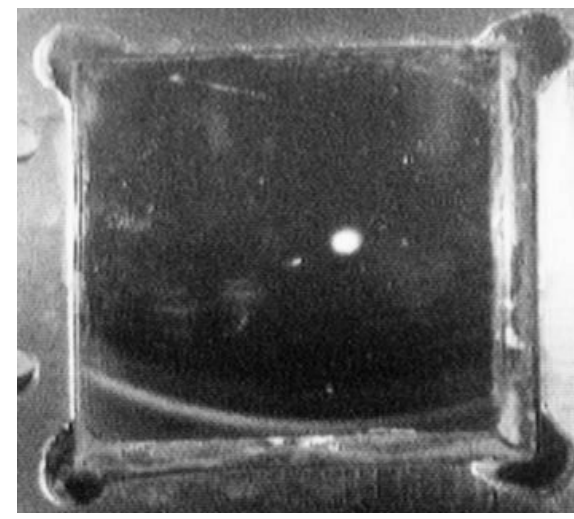

Figure 11: the electron beam spot, viewed on a $25 \mathrm{~mm}$ square phosphor screen

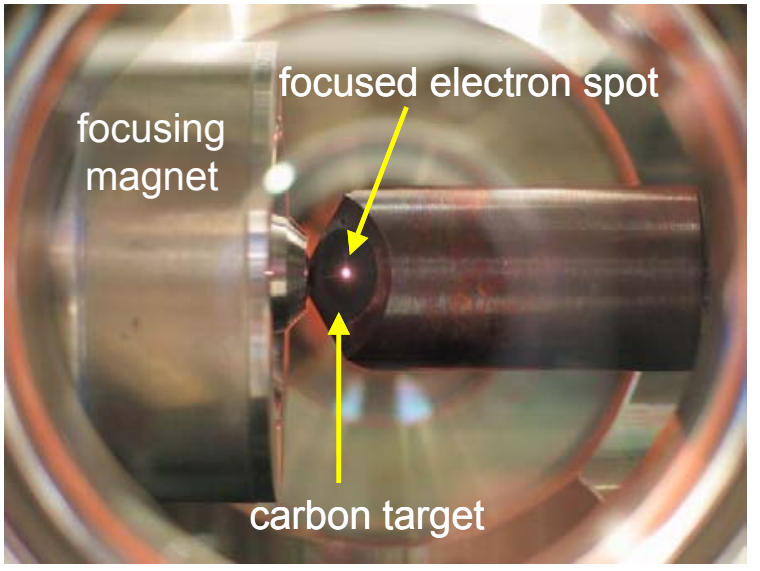

Figure 12: the electron bean spot on the carbon target 


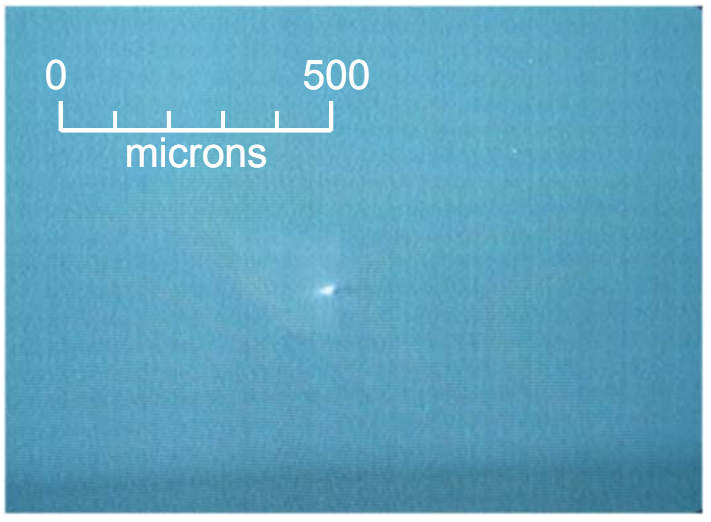

Figure 13: the electron beam spot viewed by the microscope

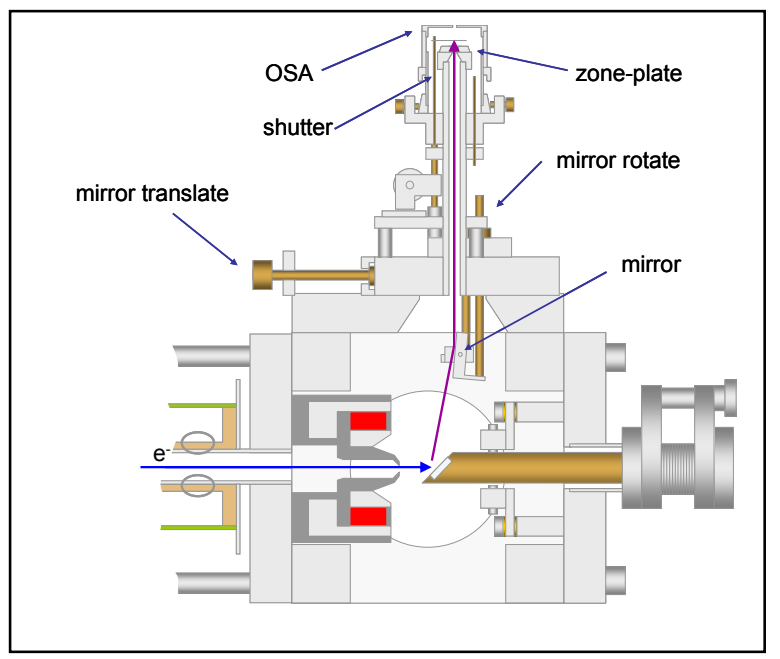

Figure 15: Scale drawing of X-ray focussing assembly

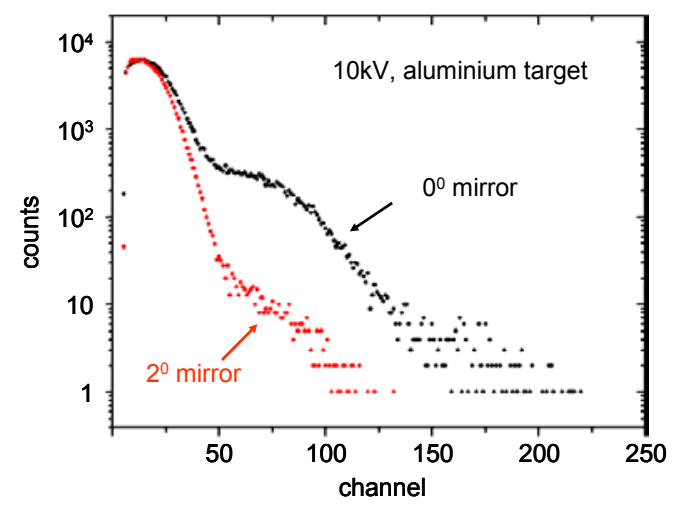

Figure 17: proportional counter spectra, showing the effect of the mirror

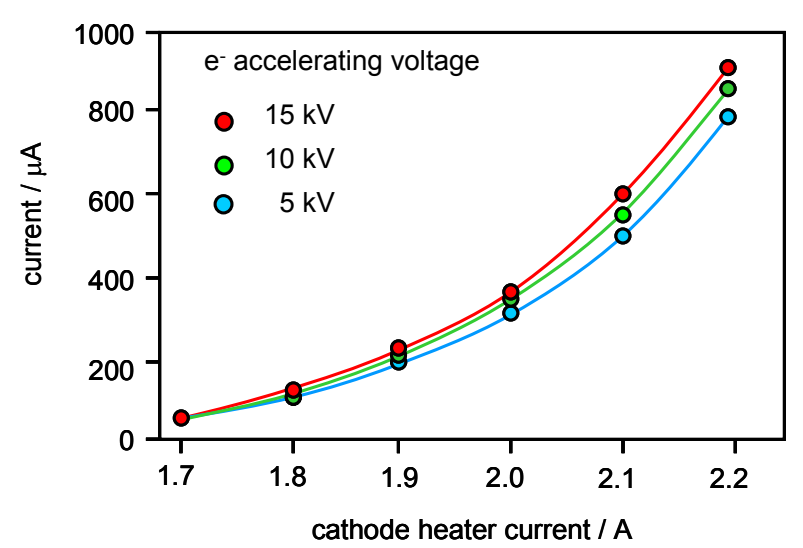

Figure 14: the electron beam current as a function of accelerating voltage and cathode heater current

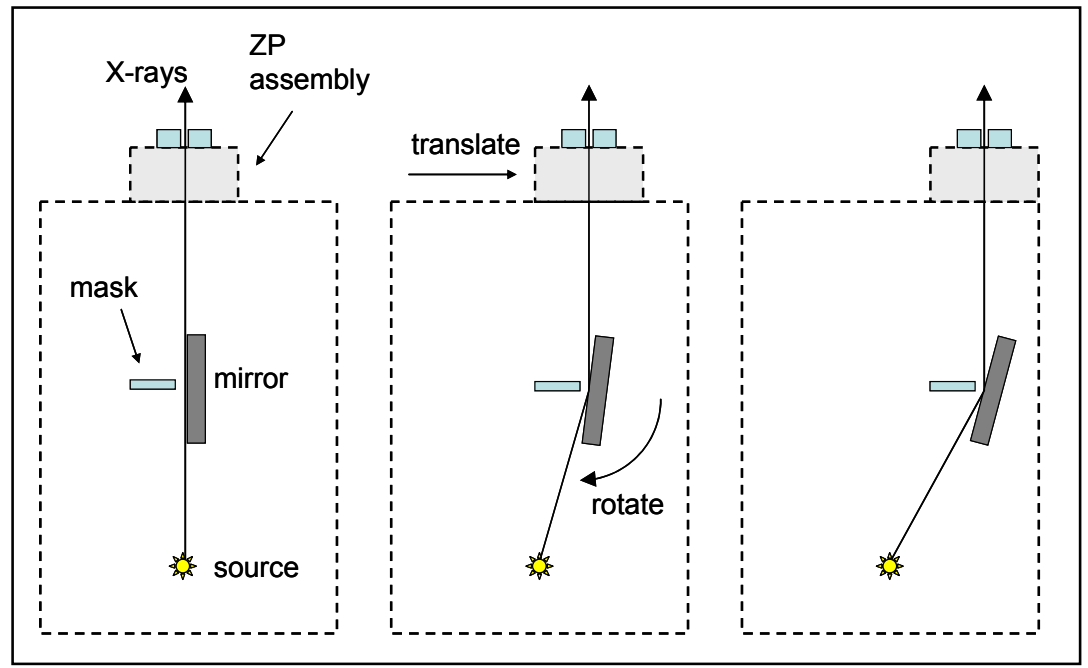

Figure 16: the action of the mirror alignment assembly

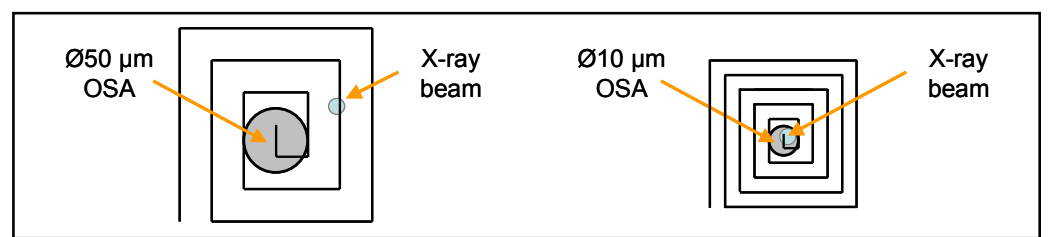

Figure 18: alignment o the OSA. Firstly, the stage moves in $25 \mu \mathrm{m}$ steps, using a $50 \mu \mathrm{m}$ OSA and the number of counts per second is logged at each step. Secondly, $2 \mu \mathrm{m}$ steps are used with a $10 \mu \mathrm{m}$ OSA, beginning at the found peak position. 


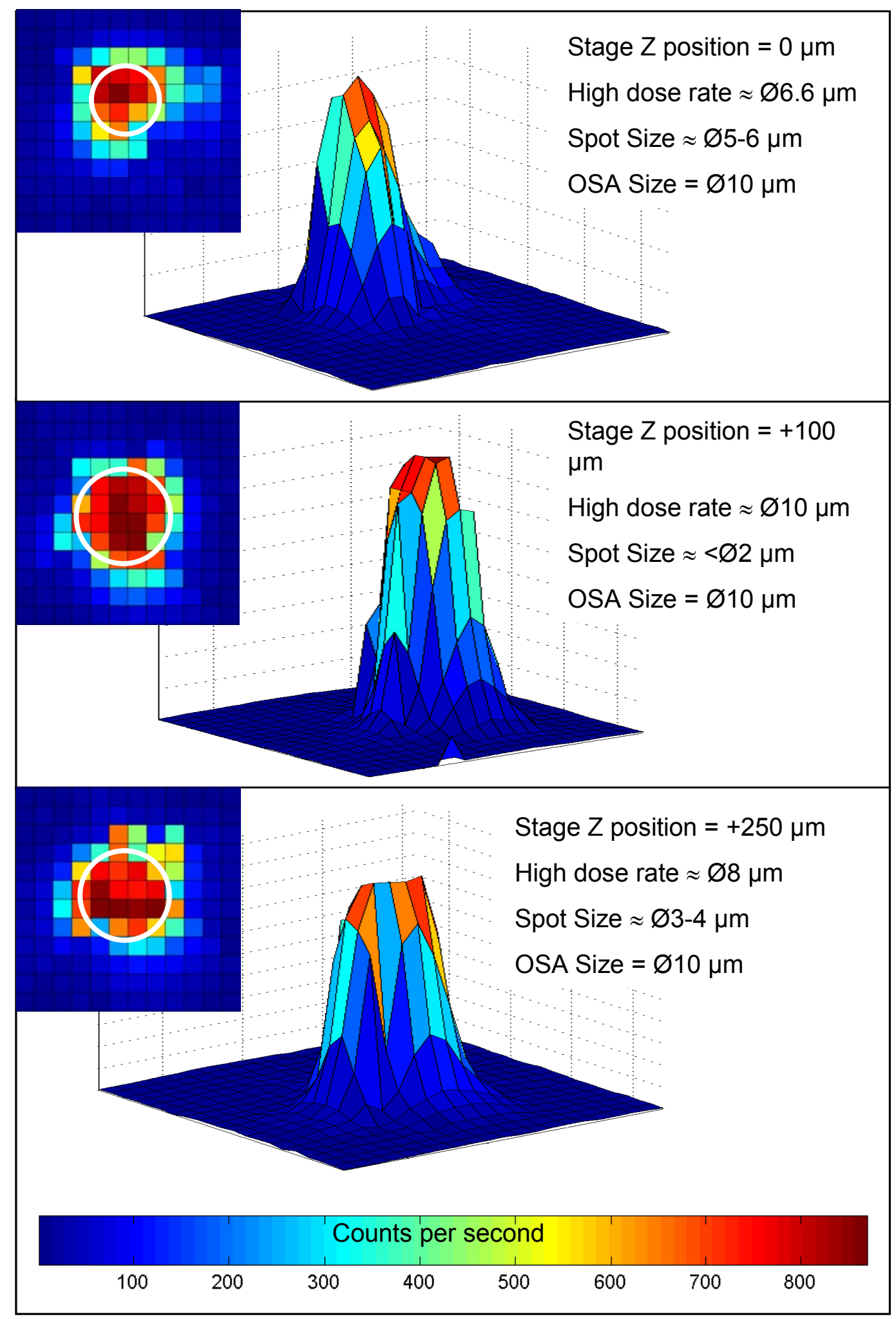

Figur 19: Establishing the position of the OSA. Pixel size is $2 \mu \mathrm{m}$. 


\section{$20 \mu \mathrm{m} Z$-shift of the film between spots}

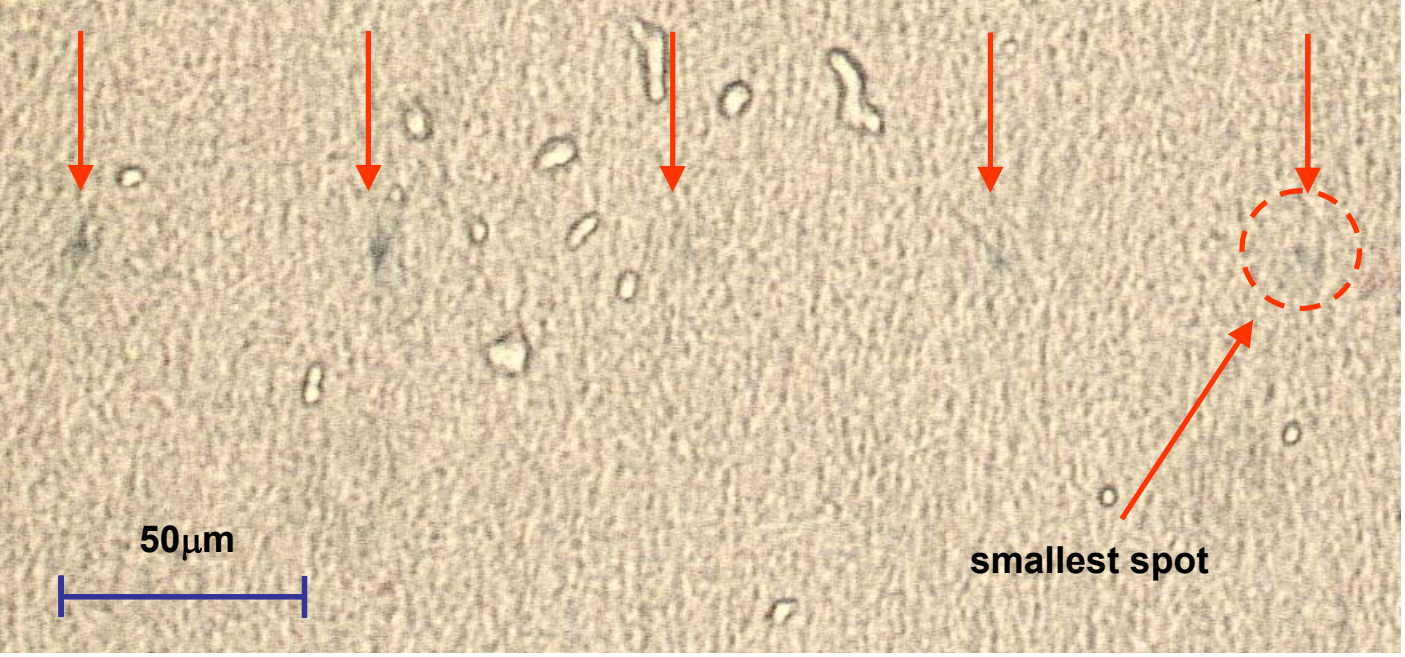

Figure 20: images of the focussed X-ray spot using radiochromic film.
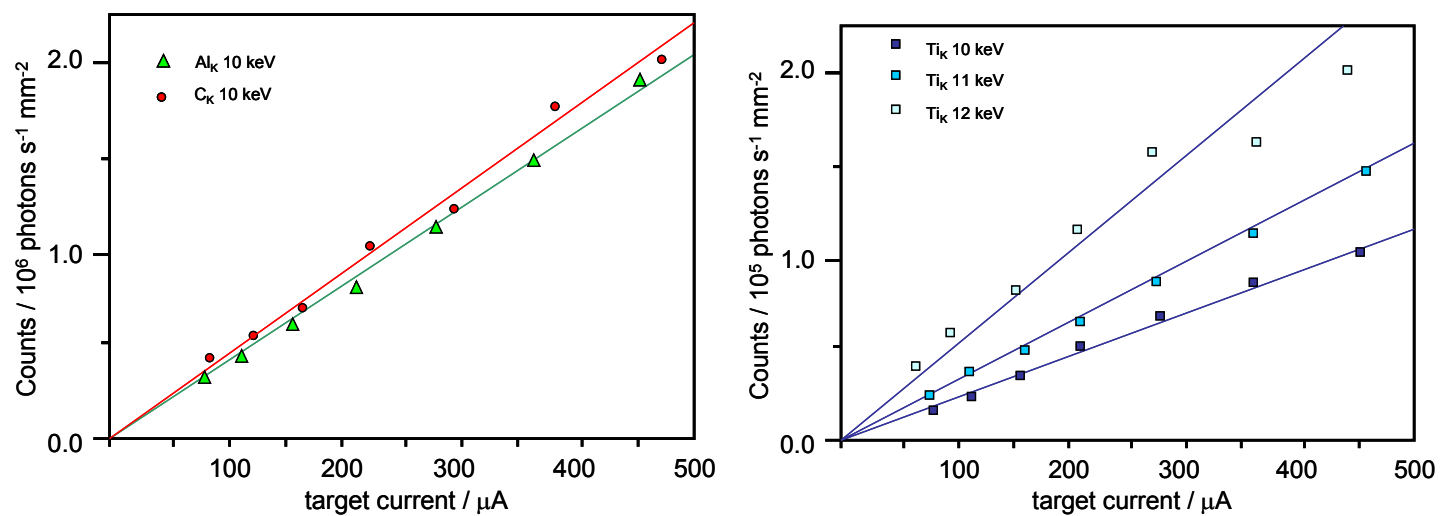

Figure 21: the measured $\mathrm{X}$-ray output (no $\mathrm{ZP}$ ) for $\mathrm{C}_{\mathrm{K}}, \mathrm{Al}_{\mathrm{K}}$ and $\mathrm{Ti}_{\mathrm{K}}$ (three electron energies) $10 \mathrm{~mm}$ from the exit window, through helium. The count rates are uncorrected for the proportional counter efficiency.

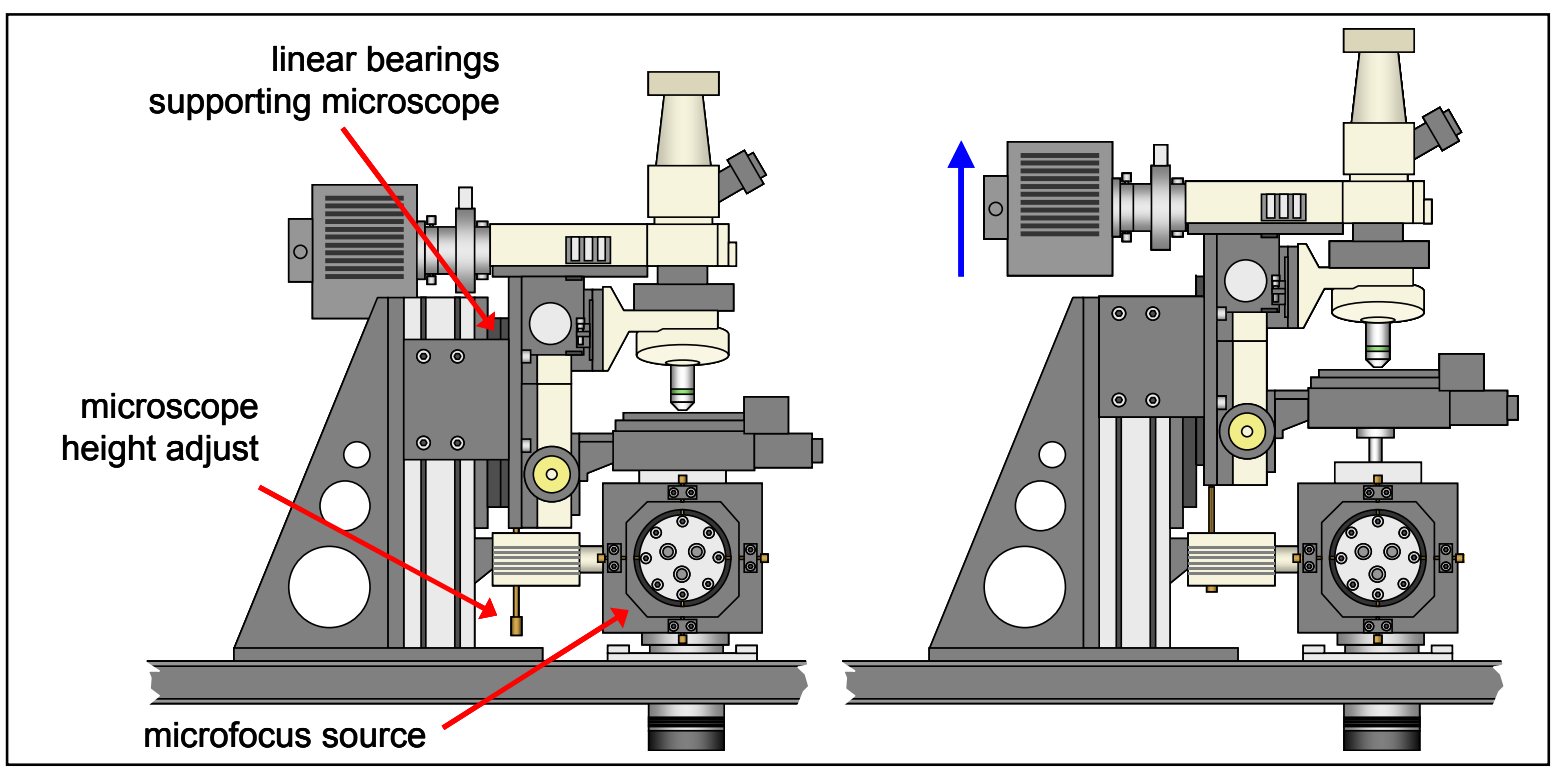

Figure 22: the mechanism for vertically aligning the microscope 


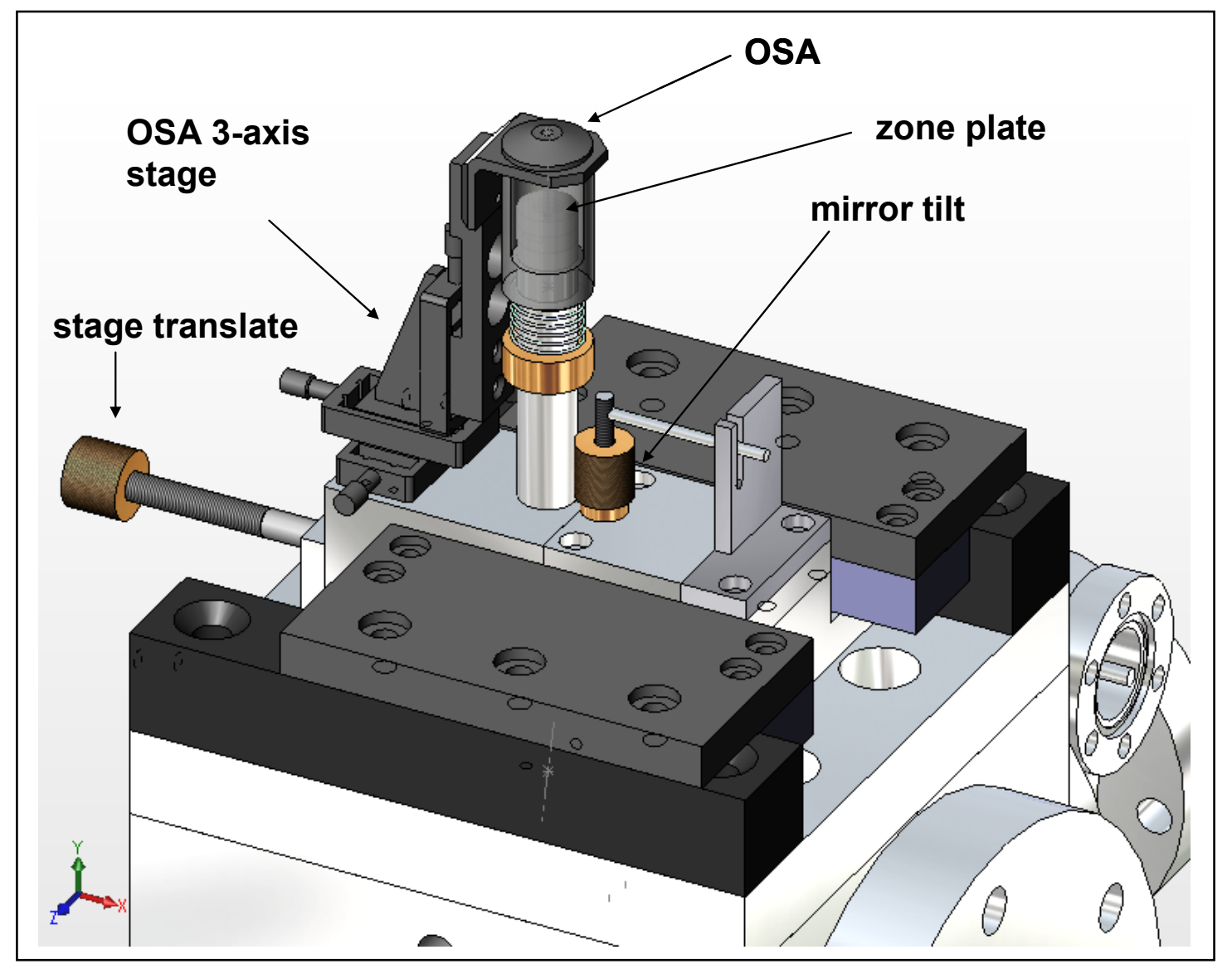

Figure 23: the new zone plate assembly, currently under construction 